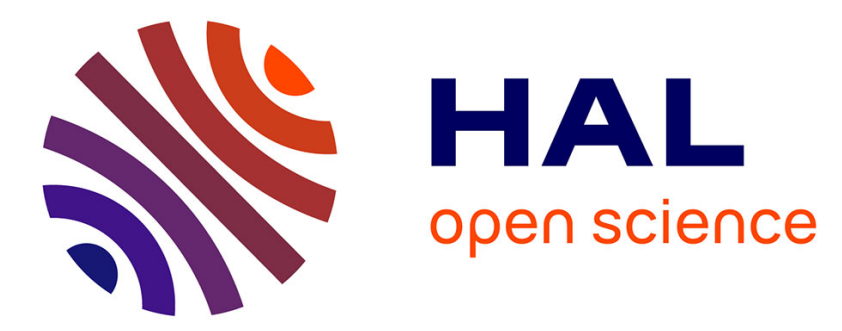

\title{
Modelling the spatial patterns of ignition causes and fire regime features in southern France: implications for fire prevention policy
}

T. Curt, T. Fréjaville, S. Lahaye

\section{- To cite this version:}

T. Curt, T. Fréjaville, S. Lahaye. Modelling the spatial patterns of ignition causes and fire regime features in southern France: implications for fire prevention policy. International Journal of Wildland Fire, 2016, 25 (7), pp.785-796. 10.1071/WF15205 . hal-01368521

\section{HAL Id: hal-01368521 \\ https://hal.science/hal-01368521}

Submitted on 19 Sep 2016

HAL is a multi-disciplinary open access archive for the deposit and dissemination of scientific research documents, whether they are published or not. The documents may come from teaching and research institutions in France or abroad, or from public or private research centers.
L'archive ouverte pluridisciplinaire HAL, est destinée au dépôt et à la diffusion de documents scientifiques de niveau recherche, publiés ou non, émanant des établissements d'enseignement et de recherche français ou étrangers, des laboratoires publics ou privés. 


\title{
Modelling the spatial patterns of ignition causes and fire regime features in southern France: implications for fire prevention policy
}

\author{
Thomas Curt ${ }^{1}$, Thibaut Fréjaville ${ }^{1}$, Sébastien Lahaye ${ }^{2}$ \\ ${ }^{1}$ Irstea EMAX, Mediterranean Ecosystems and Risks \\ 3275 route Cézanne - CS 4006, 13182 Aix-en-Provence cedex 5, France \\ Corresponding author: thomas.curt@irstea.fr \\ ${ }^{2}$ SDIS des Bouches-du-Rhône \\ 1 avenue de Boisbaudran, 13326 Marseille cedex, France \\ ${ }^{3}$ Present address: BIOGECO (UMR 1202), INRA, University of Bordeaux, 33615 Pessac, France
}

\begin{abstract}
A good knowledge of the spatiotemporal patterns of the causes of wildfire ignition is crucial to an efficient fire policy. However, little is known about the situation in southeastern France because the fire database contains unreliable data. We used data for cases with well-established causes from 1973 to 2013 to determine the location of spatial hotspots, the seasonal distribution, the underlying anthropogenic and environmental drivers, and the tendency of five main causes to generate large fires. Anthropogenic ignitions were predominant (88\%) near human settlements and infrastructures in the lowlands, whilst lightning-induced fires were more common in the coastal mountains. In denselypopulated, urban areas, small summer fires predominate because of the negligence of private individuals around their homes, or accidental ignitions near infrastructures. In rural hinterlands, ignitions due to negligence by professionals generate many medium-sized fires from fall to spring. Intentional and accidental ignitions contribute the most to the total burned area and to large fires. We conclude that socioeconomic factors partially control the fire regime, influencing the timing, spatial distribution and potential size of fires. This improved understanding of why, where and when ignitions occur provides the opportunity for controlling certain causes of ignitions, and adapting French policy to global changes. Key-words: fire activity; ignition causes; hotspots; boosted regression trees; fire policy
\end{abstract}

\section{Short summary}

The causes of wildfire ignitions vary regionally and seasonally in southern France. Ignitions resulting from negligence and accidents are more frequent in urban areas and during summer, whilst intentional ignitions are more frequent in pastures, and ignitions resulting from professional negligence more frequent in hinterlands from fall to spring. 
Author-produced version of the article published in International Journal of Wildland Fire, 2016, 25, 7, 785-796.

The original publication is available at http://www.publish.csiro.au/?paper=WF15205

DOI: 10.1071/WF15205

\section{Introduction}

Knowing the causes of wildfires and their spatiotemporal variation is crucial for developing effective fire policies and for managing landscapes in the long-term (Martínez et al., 2009; Rodrigues et al. 2014). Indeed, this information can greatly improve the effectiveness of fire prevention and detection, and the pre-positioning of fire suppression crews (; Oliveira et al., 2012), thus reducing fire risk and the probability of fires becoming large. However, such research does not yet exist for southeastern France although this area experienced, on average, 2600 ignitions and 22,000 ha burned annually over the period 1973-2013 (). Until now, French fire policy has been based on limited knowledge of the causes of fires and how they vary in space and time, although great efforts have been made in the recent years to address these limitations (Chatry et al., 2010). Developing a more efficient fire policy requires a good knowledge of the regional variations in fire activity but also of the causes of fires. Recent studies have revealed that fire activity varies greatly by region according to bioclimatic and anthropogenic conditions (Curt et al., 2014; Fréjaville and Curt 2015). As a result, ignitions, large fires, and fires during certain seasons tend to be concentrated in certain places. It is thus crucial to study the extent to which the regionalization and the seasonality of fire activity may also be linked to variations in space and time of ignition causes.

A consensus has recently emerged in Europe aimed at improving the investigation and the classification of the causes of ignitions (Cami $a$ et al., 2010). Most national fire databases, however, remain insufficient to establish accurate fire risk models (Catry et al., 2010) and contain unreliable data (Catry et al., 2008; Martínez et al., 2009; Rodrigues and de la Riva 2014) which limit the quality of models derived for the prediction of ignition and also restrict inter-country comparisons (Cami $a$ et al., 2013). It is thus crucial to select only accurate data based on relevant criteria when constructing robust models (Rodrigues and de la Riva 2014).

Ignition is the triggering factor of a wildfire, which then propagates according to the fuel, weather, and topography (Krawchuk et al., 2009; Moreira et al., 2011). The spatial and temporal patterns of ignitions, therefore, result from complex interactions between ignition sources, weather, topography and land cover (Moreira et al., 2011). In Euro-Mediterranean countries with heavily anthropized landscapes, ca. $90 \%$ of wildfire ignitions are caused by humans, while lightning accounts for only ca. $10 \%$ of ignitions (Diaz-Delgado et al., 2004; Oliveira et al. 2013; Bajocco et al., 2010; Ganteaume et al., 2013). Lightning fires are generally associated with particular topography and "fire weather", irrespective of human activities (Vazquez and Moreno 1998; Arndt et al., 2013). As humans light most fires, ignitions are related to both the motivation of humans who set fires (i.e. the use or misuse of fire) and regional variations in the main socioeconomic drivers leading to fires, such as land use (Koutsias et al., 2010; Lovreglio et al. 2010), population density (Oliveira et al. 2013; Romero-Calcerrada et al., 2010), or the presence of infrastructure (Lovreglio et al., 2010). Past research suggests that ignitions resulting from human actions are thus dependent upon socioeconomic factors (Rodrigues and de la Riva 2014; Amatulli et al. 2007) and landscape organization (Moreira et al., 2011). The landscapes of southern Europe have been severely affected by two contrasting socioeconomic changes in recent decades. In many rural areas, the 'rural exodus syndrome' of the 1950s-1960s (Moreira et al., 2011) has generally increased fire activity (Pausas and Paula, 2012) because of the widespread increase in vegetation biomass due to the decrease in agropastoral activities (Vélez, 2009), and afforestation with flammable forest species. At the same time, urban areas, dwellings, recreation areas, infrastructure and resorts have expanded into wildland and forests, thus creating fire-prone and vulnerable rural-urban interfaces (Moreira et al., 2011) and increasing the likelihood of intentional fires due to conflicts between different owners who have different lifestyles (Vélez 2009). Both changes have also increased the occurrence of large and devastating fires (San-Miguel-Ayanz et al., 2013), and considerable efforts 
have been made recently to predict their occurrence better (Moreira et al., 2010; Cardil et al., 2014; Lahaye et al., 2014). It is of interest to assess whether certain causes of ignition play a part in the occurrence of these large fires because they occur at locations and times favorable to the rapid propagation of fire.

Our goal is to better understand why, where and when ignitions occur in southeastern France in order to improve the placement of prevention and suppression efforts. For this purpose we selected wellestablished causes of ignitions from the Prométhée national fire database (1973-2013) in order to reduce uncertainties associated with location and causes, which can strongly affect predictions of fire risk (Thompson and Calkin, 2011; Rodrigues and de la Riva 2014). Five main causes were considered: natural (lightning), intentional, accidental, negligence by private individuals and negligence by professionals. We used spatial pattern analysis to determine the areas with high-concentrations (i.e. the hotspots) of each cause, and we modeled their occurrence using boosted regression trees based on socioeconomic and environmental variables. We also tested whether certain causes generated particular sizes of fires, or were more frequent in certain hours and seasons. This modeling framework aims to provide better understanding of the regional variations in the causes of ignition for operational fire management and risk assessment (see ).

\section{Materials and methods}

\section{Study area}

Our region is the southeastern part of France, which covers $80500 \mathrm{~km}^{2}$ (Fig. 1). This fire-prone area encompasses large bioclimatic, environmental and anthropogenic gradients, making it suitable for studying different ignition causes. In short, the study area includes Mediterranean lowlands (Provence, Languedoc-Roussillon, Maritime Alps), mid-elevation hinterlands and foothills (southern Alps, Cévennes, Ardèche and Pyrénées), and mountain areas (western Alps, Corsica, and Pyrénées; Fig. 1). Elevation ranges from 0 to 2000 meters a.s.l. (Fig. 1). The Mediterranean areas have low mean rainfall $\left(<700 \mathrm{~mm} \mathrm{yr}^{-1}\right)$ and high temperatures $\left(>13^{\circ} \mathrm{C}\right)$ conducive to fire activity (Fig. 2$)$, while the hinterland has a supra-Mediterranean climate with moderate rainfall (700-1150 $\left.\mathrm{mm} \mathrm{yr}^{-1}\right)$ and medium temperatures $\left(11.5-13^{\circ} \mathrm{C}\right)$, and the mountain areas have high rainfall $\left(>1150 \mathrm{~mm} \mathrm{yr}^{-1}\right)$ and low temperatures $\left(<11.5^{\circ} \mathrm{C}\right)$ which limit fire activity. The strong and dry northern Mistral and Tramontane winds are frequent in the Rhône valley and near the Mediterranean coastline, favoring summer fire activity due to fuel dryness and increased rate of spread.

This area also exhibits a range of land covers and land uses, from cultivated land and orchards with very low flammability to highly flammable forests and shrublands. Mediterranean forests are dominated by Pinus halepensis Mill. and Quercus species, while mountain forests are dominated by Pinus sylvestris L., Pinus nigra Arn., Fagus sylvatica L. and Abies alba Mill. Flammable shrublands (so-called garrigues and maquis) are common in the southernmost part of the study area. They are dominated by Quercus coccifera L., Ulex parviflorus Pourr., Cistus spp., and Erica arborea L. Human presence and activity varies from the Mediterranean coast with its high concentration of people, infrastructure and resorts to the rural hinterland with very low human density. 
We used the national Prométhée georeferenced database for the period 1973-2013 (Prométhée, 2015), which contains data on more than 100,000 wildfires systematically collected by fire crews after each intervention. For all the fire events recorded, Prométhée gives standardized information comprising the day and hour of ignition, its location on a $2 * 2 \mathrm{~km}$ grid, the cause of ignition, and the final area burned. The $2 * 2 \mathrm{~km}$ spatial accuracy of fire data is appropriate for operational fire management.

The Prométhée database regroups the causes of ignitions into five main categories: (i) natural ignitions caused by lightning (hereafter LIGHTN); (ii) accidental ignitions generated by infrastructure such as power lines, railways, vehicles, and garbage dumps (ACCID); (iii) intentional ignition by people in relation to conflicts over land or hunting, for personal interest, for gaming or pastoralism, and by arsonists or pyromaniacs (INTENT); (iv) ignitions due to negligence by professionals involved in forestry, agriculture, industry or public works (NEGLIGPROF); and (v) ignitions due to negligence by private individuals during house maintenance, handicrafts, recreation or discarding cigarette butts or hot ash (NEGLIGPRIV). Prométhée contains a large proportion of uncertain ignition causes because the assignment of a cause is generally made rapidly by fire crews based on simple assessments. Overall, $74 \%$ of the causes were noted as 'unknown' and it is likely that investigators' knowledge of causes, the instructions for completing the database and assigning each fire a cause, and possibly the motivation and the resources allocated to populating the database have changed over time and differ between regions. The systematic investigation of causes by an expert fire investigation unit is a recent development and it concerns only a small number of ignitions. To overcome this drawback, we used an indicator of the level of certainty which was assigned to each cause by the authors. It describes how strongly the people who recorded the cause hold their opinion (i.e. the investigator's confidence in the data). The level of certainty varies from certain (i.e. the cause is known with no legitimate doubt because of converging evidence from more than one source), very likely (the cause indicated is highly probable and no other option is more likely), supposed (the cause is only indicative in the light of the evidence), and unknown (no evidence or no inquiry). We only used data coded as 'certain' and 'very likely' because only these data are considered valid and appropriate for fire cause assessment. They were pooled together and are hereafter referred to as 'well established'; they represented $25.3 \%$ of the whole database (ca. 25,500 fire events) and $26 \%$ of the total area burned.

\section{Environmental and socioeconomic factors}

We selected an initial set of explanatory variables available for the whole study area which can explain ignitions, including: (i) fuel types; (ii) topographic variables; and (iii) socioeconomic variables, such as the density of population and houses, tourist pressure, or industrial infrastructure and roads networks (Table 1). In order to select the most accurate and explanatory variables, we used Multi-Linear Regression models (MLR). This allowed us to discard some redundant variables which were less informative such as elevation. All variables were spatialized at the $2 * 2 \mathrm{~km}$ grid and superposed using the ArcMap ${ }^{\mathrm{TM}} 10.2$ (ESRI Inc.) geographical information system.

\section{Determining the fire causes hotspots}

The number of ignitions varies strongly across our study area (Figure 2A), and it is crucial to determine where the hotspots (i.e. the areas with a high concentration of an attribute) are located for each type of cause in order to apply specific prevention and suppression measures. Several spatial autocorrelation statistics can be used to determine such hotspots (Koutsias et al., 2004; ). We calculated the Getis-Ord $\mathrm{G}^{*}$ statistics () using the 'spatstat' $\mathrm{R}$ package (Baddeley, 2014). The $\mathrm{G}^{*}$ statistic is an efficient and 
flexible approach for determining hotspots (see Rodrigues and de la Riva, 2014), in this case the cells with dense clusters of ignitions associated with a certain cause. $G^{*}$ compares the local neighborhood average of each cause of ignition against the global averages, and calculates a z-score which indicates the extent to which the clustering differs from a random distribution. For each cause of ignition, we considered a hotspot to exist within the $90 \%$ isopleth, which contains $90 \%$ of the total ignitions.

\section{Modeling the environmental and human drivers of ignition cause hotspots using boosted regression trees}

For each cause, we determined what the environmental and anthropogenic drivers are using a boosted regression tree procedure (BRT). Results from hotspot analysis are used to construct the dependent variable. All the pixels within a hotspot for a certain cause were coded as 1 , and the others were coded as 0 . BRT analysis is a machine learning method that has proved well-suited to exploring environmental data without the restrictive assumptions of parametric statistics (e.g. Aertsen et al., 2010; Viedma et al., 2012; Curt et al., 2015) and optimizing the predictive performance of models (De'ath, 2007). BRTs are flexible and easy to interpret (Elith et al., 2008) and they take account of collinearity between variables, which is likely to occur with anthropogenic and environmental data. The BRT procedure generates multiple regression trees based on training data and sequentially fits the residuals of the previous trees to provide a final ensemble tree - a process known as 'boosting' (De'ath, 2007). We used the 'gbm' $R$ package (Ridgeway, 2013) with a Bernoulli (logistic) error structure. Half of the data were used for building the model (the training dataset), and half to evaluate the accuracy of the classification (the validation dataset). Using the recommendations of Elith et al. (2008), the number of trees in each BRT was set automatically to 20 -fold cross-validation, we selected a bag fraction (training data randomly selected for computing each tree) of 0.5 , a shrinkage or learning rate of 0.005 which controls the learning speed of the algorithm, and a tree complexity of 5 . This generated a minimum of 3000 trees per model. The quality of the models and their predictive performance was assessed using the area under the receiving operator curve (AUC; Pearce and Ferrier, 2000). A model with an AUC $<0.6$ is considered very poor, moderately good when AUC is 0.6 to 0.9 , and excellent when AUC $>0.9$. In the first step, the BRT procedure uses all explanatory variables and indicates the effect of each variable on the response after accounting for the average effect of all variables in the model (Elith et al., 2008 Appendix S2). The final simplified model keeps only the most significant variables (the 'drop-off' step) using methods analogous to backward selection in regression (Elith et al., 2008).

\section{Temporal analysis of fire causes}

We examined the hourly and seasonal frequency of each fire cause in order to determine whether there was specific timing to certain causes. For this purpose we undertook tests of prevalence of each cause according to the time interval (hour of the day or season). Each test compares the observed proportion for each cause and each hour or season to the expected value from a null hypothesis of no time differences in cause. The test used 10,000 Monte Carlo random simulations to indicate the extent to which the observed value differs from the expected random value, and a $p$-value indicates the statistical significance thresholds. 
We tested whether certain causes generate significantly more fires of a certain size than others using tests of prevalence as described above. We derived six fire size classes $(<1$ ha, 1-10 ha, 11-50 ha, 51100 ha, 101-200 ha, and $>200 \mathrm{ha}$ ) from the Prométhée database, which correspond to the percentiles 70, 95, 97, 98 and 99 of the distribution, and to frequency size thresholds commonly used in EuroMediterranean countries (e.g. Camia et al., 2013). Each fire was assigned a fire size class. The test of prevalence compared the observed proportion for each fire cause and each fire size class against the expected value calculated using 10,000 random Monte Carlo iterations, and then tested the significance on the basis of the $p$-value.

\section{Results}

Based on the well-established causes of fire for the 1973-2013 period, this study shows that there are significant differences in the contribution of each ignition cause to fire frequency and burned area size. Ignitions due to negligence are the major cause with respect to number (ca. $60 \%$ of all ignitions), but they represent only ca. $30 \%$ of the total burned area (Table 4). Conversely, intentional ignition represents ca. $20 \%$ of all ignitions but accounts for ca. $40 \%$ of the area burned. Accidental ignitions generate ca. $19 \%$ of the total burned area and only $12 \%$ of the number of fires, in contrast to lightning fires that account for $6 \%$ and $10 \%$, respectively.

Each cause has a specific spatial pattern and also specific drivers (Fig. 4) with a major contrast between human-caused fires and lightning-induced fires. Overall, lightning-induced fires were driven by fuels whereas human-caused fires were driven by socioeconomic variables. The spatial hotspot analysis indicated that lightning fires were clearly concentrated in few large clusters in coastal or hinterland mountains (Fig. 3A). The BRT procedure indicated that these lightning hotspots corresponded to steep slopes with high cover of forest and shrublands, and low densities of population, housing, and roads (Fig. 6 in Appendix). In contrast, the human-caused fires were concentrated at low elevations with low to medium habitation density, a high density of fire suppression forces, roads, artificial land cover (i.e. urban, industrial, mines, garbage dumps), and on steep slopes with high cover by shrublands and medium-high forest cover.

Intentional ignitions were concentrated in small clusters in Corsica and the Mediterranean lowlands (Fig. 3B), which correspond to moderately populated areas with intermediate road density, at low elevations but on steep slopes, and with shrublands, pastures and agropastoral areas, artificial land cover, or forests (Fig. 7 in Appendix; Table 4). Accidental ignitions were recorded preferentially on the seashore and in the Rhône valley, in the vicinity of the main infrastructure, roads or dwellings and irrespective of fuel cover (Fig. 3C; Fig. 8 in Appendix). Ignitions resulting from professional negligence were concentrated in large clusters at mid-elevations (Fig. 3D), in areas with a high density of houses, roads and population, on moderate-to-steep slopes, in areas covered by forests, agropastoral lands and shrublands (Fig. 9 in Appendix). Ignitions due to the negligence of private individuals were more scattered (Fig. 3E). They mostly occurred in densely inhabited areas with agricultural and pastoral activity, irrespective of whether there was high fuel cover (Fig. 10 in Appendix).

Most BRT models provided good prediction of ignition causes with AUC values of $0.730 \pm 0.006$ (mean $\pm \mathrm{SE}$ ), $0.764 \pm 0.004,0.748 \pm 0.004,0.747 \pm 0.004$, and $0.772 \pm 0.003$ for lightning fires, intentional ignitions, accidental ignitions, ignitions due to negligence by professionals, and ignitions due to negligence by private individuals, respectively (Fig. 4). This allowed us to produce maps to predict the 
Author-produced version of the article published in International Journal of Wildland Fire, 2016, 25, 7, 785-796.

The original publication is available at http://www.publish.csiro.au/?paper=WF15205

DOI: 10.1071/WF15205

occurrence of ignition hotspots for the different causes (Fig. 5 in Appendix), which showed good agreemens with the maps of the observed values (Fig. 3).

We found that most ignitions had rather similar hourly distributions, with human-induced ignitions occurring preferentially between 13:00 and 17:00, while lightning fires peaked between 15:00 and 19:00. In contrast, the seasonal patterns differed between the causes: intentional or accidental ignitions and lightning fires were statistically more frequent in summer, while all ignitions due to negligence were more likely from fall to spring $(p<0.05$; Table 2$)$.

The prevalence tests indicate that there is a relationship between fire size and ignition cause. Intentional ignitions preferentially generated fires larger than 10 ha, and, in particular, large fires $>200$ ha $(p<$ 0.05; Table 3). Accidental ignitions were not associated with generating a statistically significant occurrence pattern with respect to fire size with the exception of a positive effect for large fires $(>200$ ha). In contrast, ignitions due to negligence by professionals preferentially generated small and medium fires $(p<0.05$; Table 3$)$, while ignitions due to negligence by private individuals generated very small fires $<1$ ha $(p<0.05$; Table 3$)$. Lightning ignitions generated more very small fires than expected according to a random distribution and fewer medium fires $(p<0.05$; Table 3$)$. In total, some humancaused fires (i.e. accidental and intentional) generate larger fires than lightning fires.

\section{Discussion}

We demonstrated that each of the five main causes of wildfire ignition displays typical features as concerns spatial location, drivers, seasonality and propensity to generate certain sizes of fires (summarized in Table 4). Accordingly, we affirm that the causes of ignition contribute to explain the regional variations in fire regime in southeastern France in combination with climate and environmental factors (Fréjaville and Curt, 2015). Only the daily patterns are similar for all human-caused ignitions, peaking between 13:00 and 17:00, while lightning fires peaked between 15:00 and 19:00, thus fitting with data for Europe as a whole (Ganteaume et al., 2013). Overall, 95\% of the ignitions occur between 07:00 and 22:00 and coincide with the peaks of human (Vélez, 2009) and lightning activity (Poelman et al. 2013), and of fuel dryness (Sandé Silva et al., 2010).

Two human causes contribute the most to the fire occurrence in our study area. Intentional ignitions are not the most frequent but are those that are responsible for the highest proportion of burned area and that preferentially generate large fires. Indeed, they occur preferentially in summer when fire weather is conducive to fire propagation and wildland fuels are dry; during this period lighting fires is strictly forbidden. They are more frequent in shrublands, forests and pastures where they can lead to highintensity and rapid crown fires which are difficult to suppress (Curt et al., 2013). The individuals who ignite such fires intentionally do so with the expectation of causing significant damage and gaining financial interest with respect to land property, pastoralism or hunting, or solving a conflict; a special case is that of arsonists who expect to generate large fires in order for the pleasure of seeing fire or firemen activity. Hotspots of intentional ignitions are frequent in Corsica and in the coastal lowlands, where pastoralism and conflicts concerning land property are more likely. Accidental ignitions occur throughout the year, although most frequently in summer because of favorable environmental conditions for ignition, and they generate a significant proportion of large fires. They are clearly concentrated in areas with high levels of wildland-urban interface, resorts, tourism, and near infrastructure such as road corridors, railways, garbage dumps, and electricity lines. Hotspots are located in the Rhône valley, on the Mediterranean coastline, and in southern Corsica. Ignitions resulting from negligence are the most numerous although they tend to result in small to medium fires. They typically peak from fall to winter 
when fuels are not dry, when fire use is temporarily authorized for managing fuels in forests, pastures, and gardens. Those ignited by private individuals during home maintenance or leisure are mostly small because they generally occur in urban areas where fuel is limited or managed, and where the intervention of firefighters is rapid. Many are localized in the vicinity of highly urbanized areas of the eastern Mediterranean coastline. Fires ignited by professionals are mainly small to medium. This probably relies to the fact that professionals are experimented and generally use fire in moderate weather conditions (fall to spring) during which they can control propagation.

The features typical of each ignition cause account for the regional variations of fire regime in southeastern France (i.e. the so-called 'pyroregions'; Curt et al., 2014). Indeed, areas with high burned area (Fig. 2) are clearly superimposed on areas with high density of human-caused ignitions (Fig. 3 BE). They include the Mediterranean lowlands, Corsica (35\% of the number of fires and $37 \%$ of the burned area), and the Maritime Alps. In these areas intentional and accidental ignitions predominate during summer due to the presence of urban areas and infrastructure. These pyroregions combine many factors triggering fires: hot weather, heavy fuels, and high human activity (Frejaville and Curt 2015; Curt et al., 2014). Mid-elevation hinterland and rural areas of Cévennes and Ardèche also have high fire activity, but mainly from autumn to spring for the management of vegetation. In these pyroregions, fuel is generally abundant, and fire size remains moderate because the weather is not conducive to large fires from fall to spring. This contrast between highly urbanized areas and rural areas may diminish to the increasing urban sprawl into rural areas, as observed in many European countries (Moreira et al., 2011). Together with the expansion of shrubby and forest fuels in the landscape and with climate change (Frejaville and Curt 2015), this may increase fire risk. In this context it is of great interest to monitor changes in population, infrastructure, land cover and land uses in order to improve the prediction of fire hazards and to adapt the fire policy in the long-term. Intentional and accidental ignitions, which have the propensity to generate large and destructive fires, should be especially monitored in the context of climate change.

Lightning-caused fires differ drastically from human-caused fires. They are concentrated in few large clusters in mountains and coastal areas with low anthropogenic pressure but high fuel biomass, thus confirming that they can spread only under favorable environmental conditions (Nastos et al., 2014). Their spatial patterns resemble that of summer lightning strikes in France (Poelman et al. 2013), supporting the idea that lightning strikes may cause a fire only when they reach sufficiently dry surface fuel (Wotton et al., 2003; ). In our study, lightning-caused fires rarely grew large, in contrast to the situation recorded in Greece (Nastos et al., 2014). This may be due to the fact that surface fuels are not dry enough in summer in our cool mountains to allow fires to become large. Lightning fires should be monitored even if they cannot be prevented (Martinez et al., 2009) because they represent $11.3 \%$ of all ignitions and up to $25 \%$ in the Southern Alps (Fréjaville et al., 2016), and because they develop in remote areas where they are difficult to detect and to suppress (Vacik et al., 2011). Lightning fires could become more frequent with climate change, as shown in Switzerland (Reineking et al.,2010) and Austria (Vacik et al., 2011; Muller et al., 2013. ).

\section{Implications for fire policy: the leverage effect}

Assessing why, where and when wildfire ignitions occur should allow the targeting of prevention in southeastern France, and provide an opportunity to reduce fire risk, especially the occurrence of large fires. Considerable efforts have been made in France during the past decade to better prevent and suppress fires, resulting in a great decrease in the number of ignitions and of the total area burned each year (Chatry et al., 2011; Rodrigues et al., 2013; Fréjaville and Curt, 2015). However, firefighters face 
three major issues: (i) the current strategy for pre-positioning fire crews still relies on limited knowledge about the location of ignitions, their seasonal variations and their drivers; (ii) the occurrence of large and destructive fires in summer; and (iii) the investment in fire suppression may decrease in certain regions (Chatry et al., 2011). Based on this study, we propose better targeting of the local strategy in highly fireprone Mediterranean areas, concentrating on summer intentional ignitions in northern Corsica and Provence. Many of those fires were ignited in pastures by local people to protest against land issues, taxes, regulations or real-estate speculation. A significant decrease in these fires has recently resulted from regulation of livestock premiums and agreements about land management between the public decisions-makers and the local population. Stabilizing or improving this situation in the long-term would greatly decrease fire activity in France and the pressure exerted on fire crews. In Mediterranean areas with high human and infrastructure density, surveillance (pre-positioning) is already performed. Vegetation management (grass mowing and shrub clearing) would also decrease fire risk associated with accidental ignitions or ignitions due to the negligence of private individuals. It has proved very efficient in limiting ignition and propagation but it is rarely undertaken. Although unpopular, law enforcement may be the only solution because urban areas require most of resources for fire suppression and would increase with any expansion of rural-urban interfaces and population (Badia-Perpinya and PallaresBarbera, 2006). Information and educational campaigns directed at private individuals would also help because many people have limited knowledge of fire risk and fire use (Chatry et al., 2010; Montiel et al., 2010). Some municipalities have already banned vegetation fires in order to limit fire risk and the emission of particles into the atmosphere, and this is probably the best solution. In this case, efforts should be focused on grass-mowing and shrub-clearing. In hinterland forests, and pastoral and agricultural lands, reducing ignitions due to the negligence of professionals from fall to spring is a priority. Efforts should be focused on better information about the daily fire danger from fall to spring, banning fires when the fire weather risk is moderate to high, specific training courses for less experienced professionals, demonstrations of prescribed burning by experts, and specific educational campaigns. The prevention and suppression strategy is currently probably insufficient from fall to spring in these areas. It should also be extended in fall as the season at risk seems to extend beyond the end of summer (Fréjaville and Curt 2015).

\section{Conclusion}

This study presents information and models for understanding and reducing ignitions resulting from different causes in southeastern France, based only on information classified as "well-established" and suited for a local-to-regional strategy of prevention and pre-positioning of fire crews. It reveals the importance of the uses and misuses of fire by people, which account for $94 \%$ of the total burned area, and a regional and seasonal distribution for each cause that fits with the regionalization of fire activity (Fréjaville \& Curt 2015). Negligence and intentional ignitions predominate with respect to fire number and the area burned, respectively. A zero burn policy (i.e. banning all fires) is neither realistic nor desirable in Europe (Silva et al., 2010). We thus believe that preventing and suppressing fires requires local compromises between short- and long-term actions, acceptable by the population (Montiel and Herrero, 2010; Vélez 2009; Collins et al., 2013). The predicted changes in socioeconomics, landscape organization and land use could result in new patterns of ignition causes in future decades, and this may in turn significantly alter the future fire regime in a synergistic or antagonistic way with climate change (Fréjaville and Curt 2015). In the future, georeferenced data for ignition with decametric accuracy, more reliable and harmonized databases on fires (Camia et al. 2010; Collective 2011) and standardized description of ignition causes (Camia et al., 2013) would favor a better European policy for fire prevention and suppression in a context of global changes (Bedia et al., 2014). 
Author-produced version of the article published in International Journal of Wildland Fire, 2016, 25, 7, 785-796.

The original publication is available at http://www.publish.csiro.au/?paper=WF15205

DOI: 10.1071/WF15205

\section{Acknowledgements}

We greatly acknowledge the contributors to the Prométhée fire database. Financial support was provided by the FUME Project under the European Union's Seventh Framework Program (FP7/2007-2013). 


\section{References}

Table 1. Summary of the environmental and socioeconomic variables used for the boosted regression tree (BRT) modelling

\begin{tabular}{|c|c|c|c|}
\hline Name & Acronym & Description & Data Source \\
\hline Forest Cover & FOR & $\begin{array}{l}\text { Cover of forests (all types) computed as a } \\
\text { percentage of the } 2 * 2 \mathrm{~km} \text { pixel }\end{array}$ & $\begin{array}{l}\text { Corine Land Cover database (2000 and 2006) and } \\
\text { National Forest Inventory database }\end{array}$ \\
\hline $\begin{array}{l}\text { Shrubland Cover (ha, log- } \\
\text { transformed) }\end{array}$ & SHRUB & $\begin{array}{l}\text { Cover of shrublands (all types) computed as } \\
\text { a percentage of the } 2 * 2 \mathrm{~km} \text { pixel }\end{array}$ & $\begin{array}{l}\text { Corine Land Cover database (2000 and 2006) and } \\
\text { National Forest Inventory database }\end{array}$ \\
\hline $\begin{array}{l}\text { Artificial Cover (ha, log- } \\
\text { transformed) }\end{array}$ & ARTIF & $\begin{array}{l}\text { Cover of artificial surfaces computed as a } \\
\text { percentage of the } 2 * 2 \mathrm{~km} \text { pixel }\end{array}$ & Corine Land Cover database (2000 and 2006) \\
\hline No Fuel Cover (ha, log-transformed) & NOFUEL & $\begin{array}{l}\text { Cover of areas with no flammable fuel such } \\
\text { as urban areas }\end{array}$ & Corine Land Cover database (2000 and 2006) \\
\hline Fuel Cover (ha, log-transformed) & FUELCOV & $\begin{array}{l}\text { Connectedness of flammable fuels in the } 2 * 2 \\
\mathrm{~km} \text { pixel }\end{array}$ & $\begin{array}{l}\text { Corine Land Cover database (2000 and 2006) and } \\
\text { National Forest Inventory database }\end{array}$ \\
\hline Slope Angle $\left(^{\circ}\right)$ & SLOPE & Slope angle & $\begin{array}{l}\text { Digital Elevation Model (resolution } 100 \mathrm{~m} \text { ) } \\
\text { National Geographic Institute }\end{array}$ \\
\hline Elevation (meters asl) & ELEV & Elevation above sea level & $\begin{array}{l}\text { Digital Elevation Model (resolution } 100 \mathrm{~m} \text { ) } \\
\text { National Geographic Institute }\end{array}$ \\
\hline $\begin{array}{l}\text { Density of infrastructure (n, log- } \\
\text { transformed) }\end{array}$ & INFRASTR & $\begin{array}{l}\text { Density all industrial infrastructure (e.g. } \\
\text { power plants and garbage dumps) and } \\
\text { networks including railways }\end{array}$ & $\begin{array}{l}\text { National Geographic Institute, and French Ministry } \\
\text { for Industry (communal level) }\end{array}$ \\
\hline Density of roads (n, log-transformed) & ROAD & $\begin{array}{l}\text { Density of roads of all categories in the } 2 * 2 \\
\mathrm{~km} \text { pixels }\end{array}$ & $\begin{array}{l}\text { Digital Elevation Model (resolution } 100 \mathrm{~m} \text { ) } \\
\text { National Geographic Institute, and French Ministry } \\
\text { for Transport (communal level) }\end{array}$ \\
\hline
\end{tabular}




\begin{tabular}{|l|l|l|l|}
\hline Index of tourist infrastructure & TOURIND & $\begin{array}{l}\text { Density of tourist infrastructure and activities } \\
\text { including resorts, hotels, camping, pooled } \\
\text { into a synthetic index }\end{array}$ & $\begin{array}{l}\text { Digital Elevation Model (resolution 100 m) } \\
\text { National Geographic Institute, and French Ministry } \\
\text { for Tourism (communal level) }\end{array}$ \\
\hline Index of Unemployment & UNEMPL & Unemployment rate (2010) & National Geographic Institute (communal level) \\
\hline
\end{tabular}

Table 2. Test of prevalence of each cause of ignition according to the season. The table indicates the observed proportion for each cause and each season, and in parentheses is the difference between the observed value and the predicted value calculated using 10,000 random (Monte Carlo) iterations. Negative differences in parentheses (-) indicate that ignitions are less frequent than expected if randomly distributed, and positive values $(+)$ indicate that ignitions are more frequent than expected. The test indicates the statistical significance threshold: $* \mathrm{p}<0.05 ; * * \mathrm{p}<0.01 ; * * * \mathrm{p}<0.001$

\begin{tabular}{cccccc}
\hline \multicolumn{7}{c}{ Season } \\
\hline Cause of Ignition & SPRING & SUMMER & AUTUMN & WINTER & Total \\
\hline LIGHTNING & $0.05(-0.05) * * *$ & $0.2(+0.1)^{* * *}$ & $0.02(-0.08)^{* * *}$ & $0(-0.1)^{* * *}$ & 0.10 \\
\hline INTENTIONAL & $0.11(-0.09)^{* * *}$ & $0.31(+0.11)^{* * *}$ & $0.16(-0.04)^{* * *}$ & $0.08(-0.12)^{* * *}$ & 0.20 \\
\hline ACCIDENTAL & $0.12(-0.01)$ & $0.17(+0.04)^{* * *}$ & $0.11(-0.01)$ & $0.05(-0.07) * * *$ & 0.12 \\
\hline $\begin{array}{c}\text { NEGLIGENCE } \\
\text { PROFESSIONAL }\end{array}$ & $0.43(+0.07)^{* * *}$ & $0.17(-0.2)^{* * *}$ & $0.47(+0.11)^{* * *}$ & $0.63(+0.27)^{* * *}$ & 0.37 \\
\hline $\begin{array}{c}\text { NEGLIGENCE } \\
\text { PRIVATE }\end{array}$ & $0.29(+0.08)^{* * *}$ & $0.16(-0.05)^{* * *}$ & $0.23(+0.02)^{* *}$ & $0.23(+0.02)^{* * *}$ & 0.21 \\
\hline
\end{tabular}


Table 3. Test of prevalence of each cause of ignition according to the fire size classes. The table indicates the observed proportion for each cause and each fire size class, and in parentheses is the difference between the observed value and the predicted value calculated using 10,000 random (Monte Carlo) iterations. Negative differences in parentheses (-) indicate that ignitions are less frequent than expected if randomly distributed, and positive values $(+)$ indicate that ignitions are more frequent than expected. The test indicates the statistical significance threshold: $* \mathrm{p}<0.05 ; * * \mathrm{p}<0.01 ; * * * \mathrm{p}<0.001$

\begin{tabular}{|c|c|c|c|c|c|c|c|}
\hline \multirow[b]{2}{*}{ Fire Causes } & \multicolumn{7}{|c|}{ Fire Size Classes (ha) } \\
\hline & $<1$ & $1-10$ & $11-50$ & 51.100 & 101.200 & $>200$ & Total \\
\hline LIGHTNING & $0.12(+0.02) * * *$ & $0.06(-0.04) * * *$ & $0.04(-0.06) * * *$ & $0.07(-0.03)$ & $0.09(-0.01)$ & $0.07(-0.03)$ & 0.10 \\
\hline INTENTIONAL & $0.2(0)$ & $0.18(-0.02) * * *$ & $0.29(+0.1) * * *$ & $0.36(+0.16) * * *$ & $\begin{array}{c}0.42(+0.22) \\
* * *\end{array}$ & $0.41(+0.22) * * *$ & 0.20 \\
\hline ACCIDENTAL & $0.12(0)$ & $0.12(0)$ & $0.12(0)$ & $0.14(+0.01)$ & $0.08(-0.04)$ & $0.2(+0.08) * *$ & 0.12 \\
\hline $\begin{array}{l}\text { NEGLIGENCE } \\
\text { PROFESSIONAL }\end{array}$ & $0.31(-0.06) * * *$ & $0.49(+0.12) * * *$ & $0.39(+0.03)$ & $0.31(-0.06)$ & $0.28(-0.09) *$ & $0.16(-0.21) * * *$ & 0.37 \\
\hline $\begin{array}{c}\text { NEGLIGENCE } \\
\text { PRIVATE }\end{array}$ & $0.25(+0.04) * * *$ & $0.15(-0.06) * * *$ & $0.15(-0.06) * * *$ & $0.12(-0.09) * * *$ & $0.14(-0.07) *$ & $0.16(-0.06)$ & 0.21 \\
\hline
\end{tabular}


Table 4. Classification of the main fire causes in southeastern France. The table shows, for each cause, an indication of their frequency based on the Prométhée database, the predominant fire season, the predominant location of hotspots, the main drivers, the probability of generating large fires (>100 ha), and the main management options

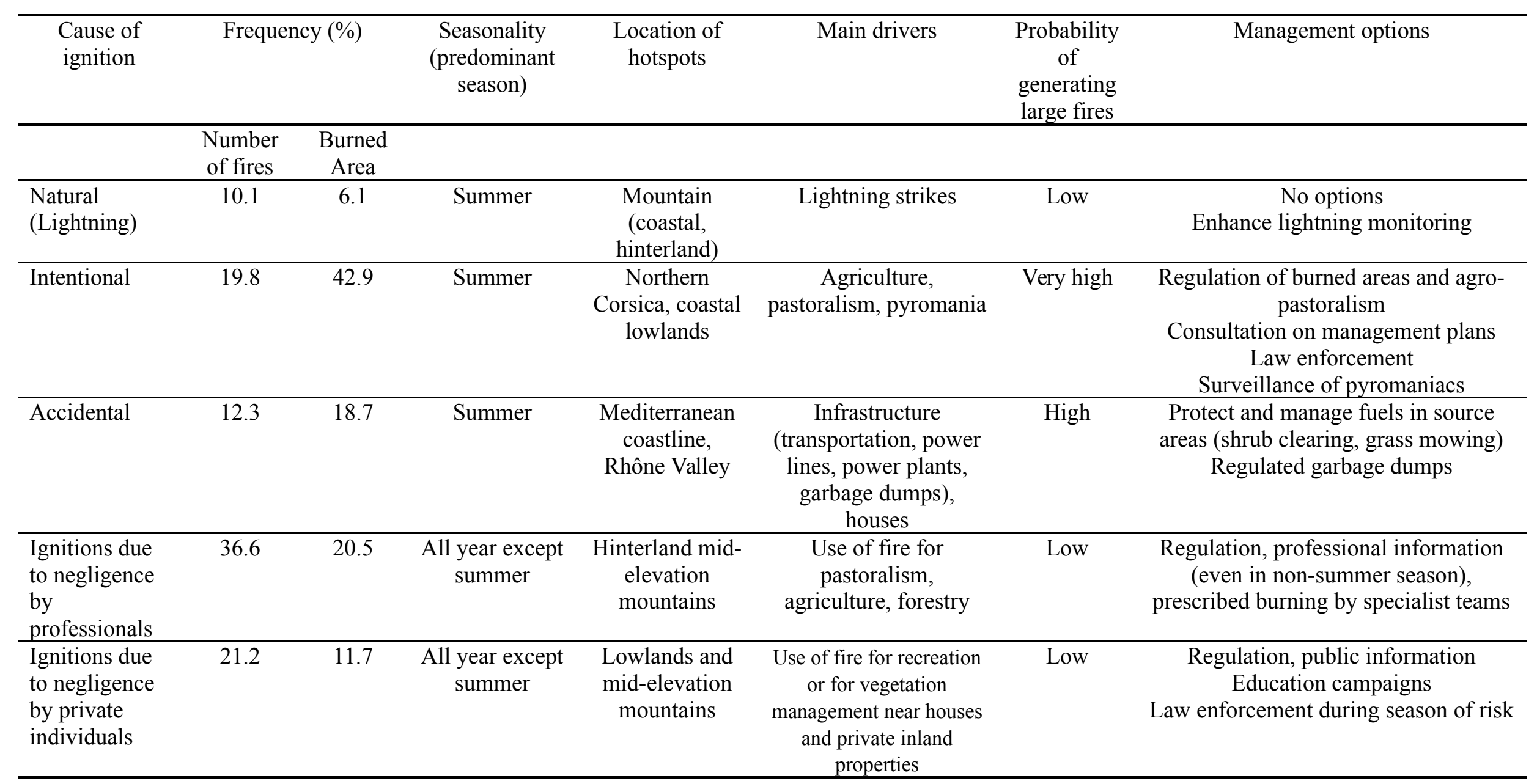


Figure captions

Fig. 1. Location of the study area and map of elevation

Fig. 2. Cumulated number of fires and total burned area in the study area (1973-2013) according to the Prométhée fire database. Pixels are $2 * 2 \mathrm{~km}$

Fig. 3. Location of the hotspots for each main fire cause. The hotspots correspond to the isopleth surrounding $90 \%$ of ignitions, determined using the Getis-Ord G* statistics

Fig. 4. Relative contribution of the variables to the final BRTs for each cause. The variables are regrouped into the main classes (fuels, topography, and socioeconomic variables) 
Fig. 1

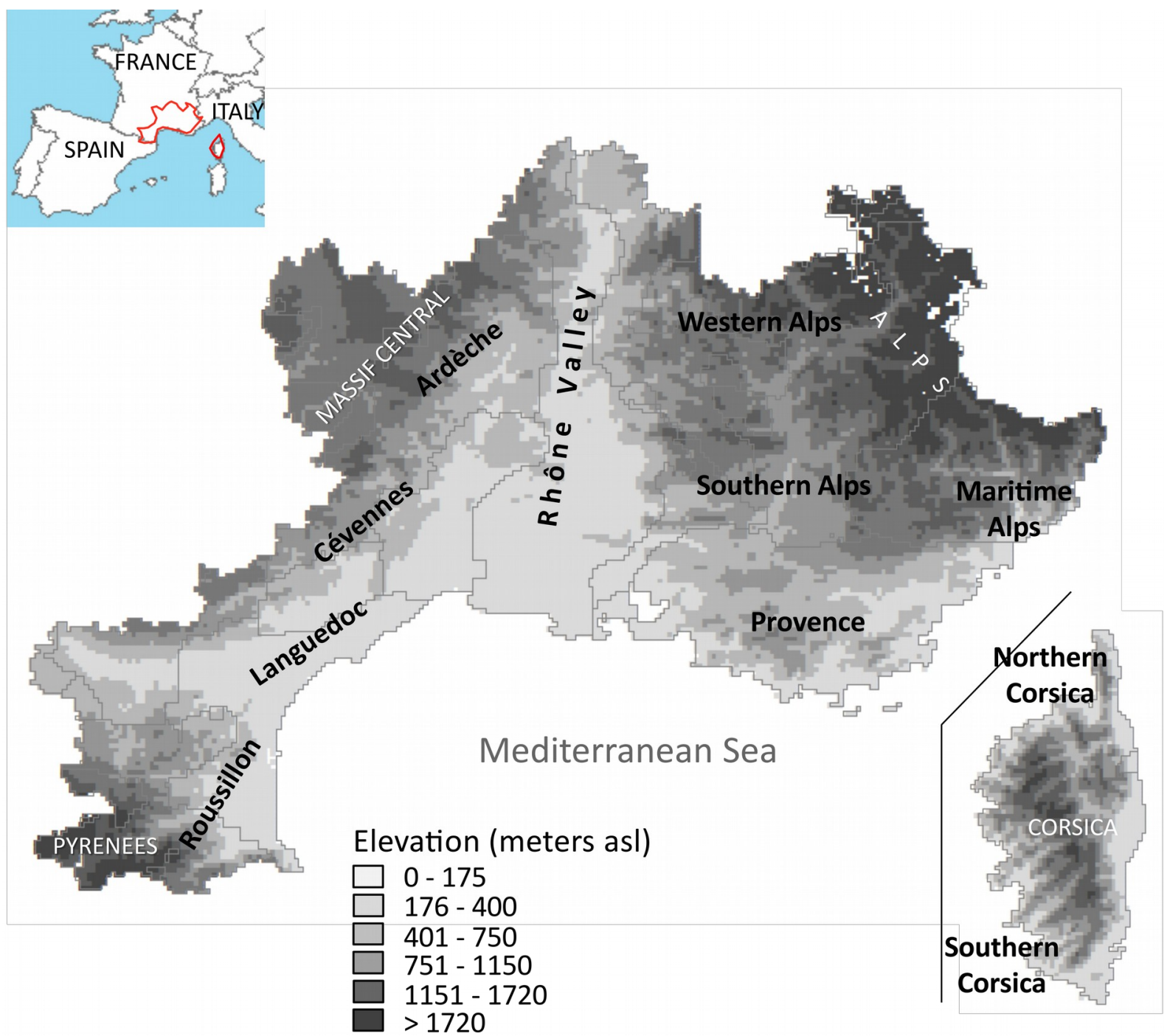


Fig. 2
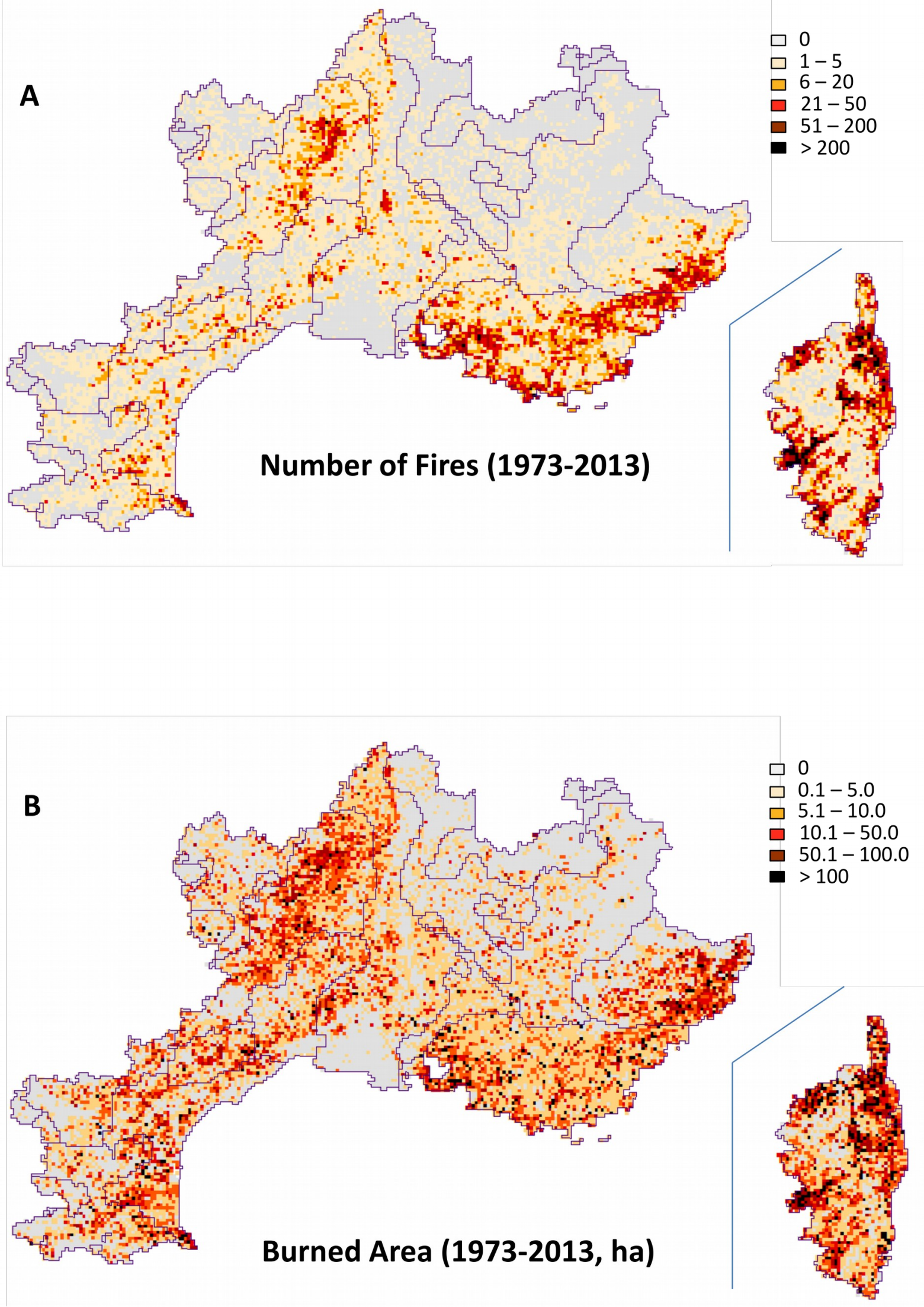
Fig. 3

A
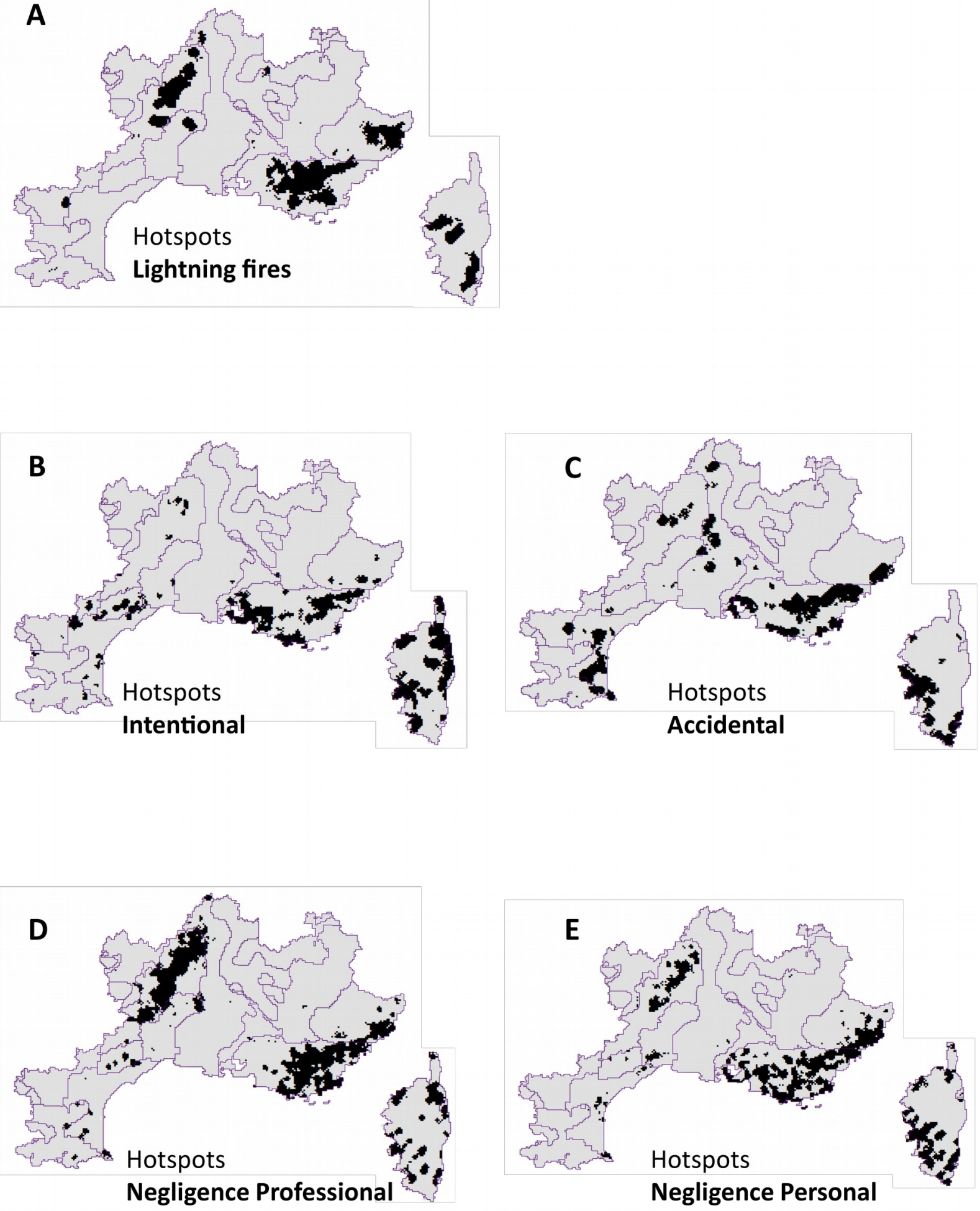
Fig. 4
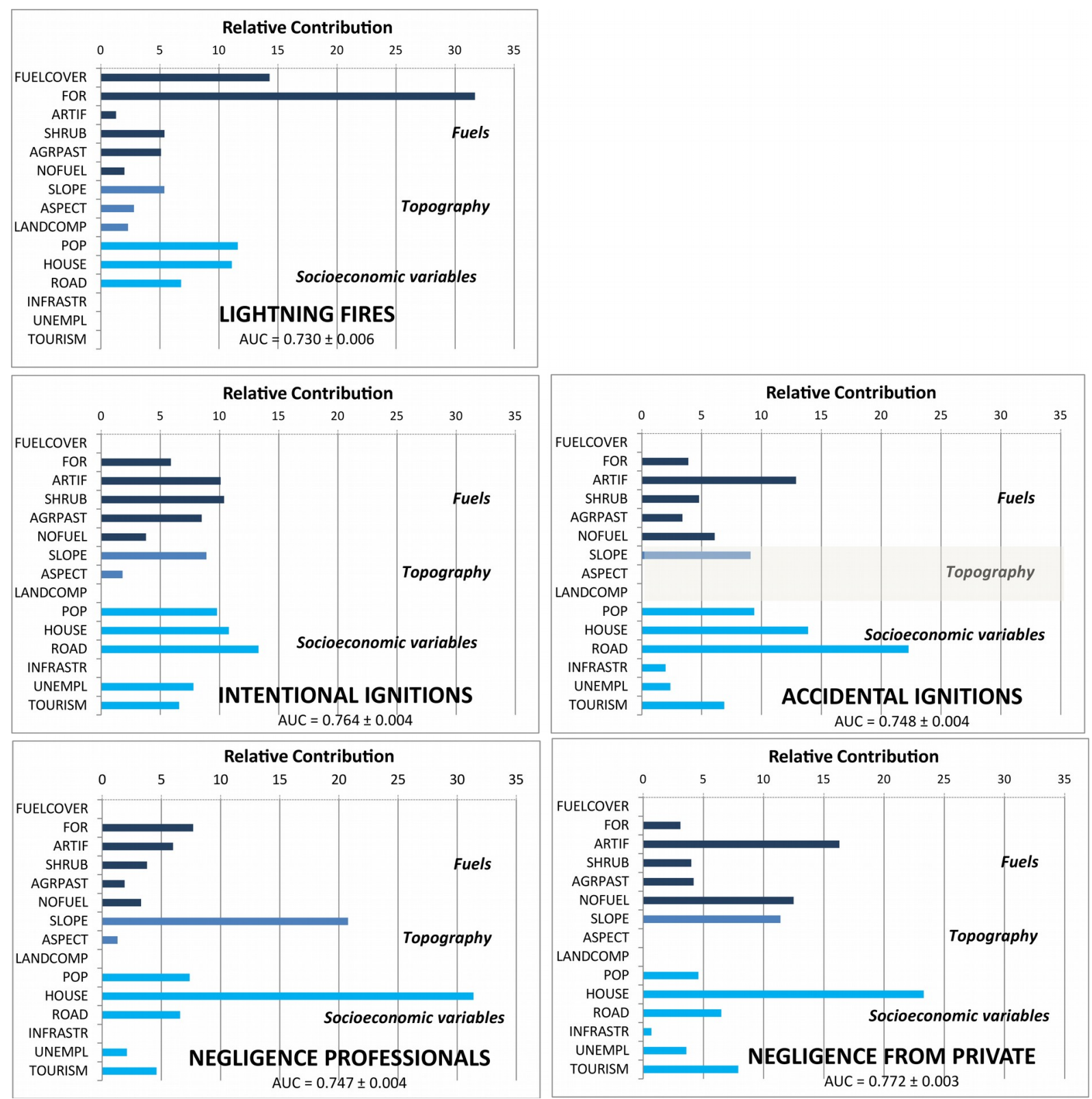
Appendices

Fig. 5. Probability of ignition for each cause modeled using the BRT procedure. Values are the fits from the final BRT model

Fig. 6. Boosted regression trees for the lightning fires (FOR: density of forests; FUELCOV: covering by flammable fuels; POP: population density; HOUSE: housing density; ROAD: road density; SHRUB: shrub density; AGRPAST: density of agropastoral lands; SLOPE: slope angle; ASP: predominant aspect; LANDCOMP: index of landscape complexity; ARTIF: density of artificialized land covers). For details see table 1

Fig. 7. Boosted regression trees for the intentional fires. The curve represents the mean value for 20 models. Values located above 0 are statistically significantly and positively associated with intentional fires, while values below 0 are statistically significantly and negatively associated with intentional fires. The stars indicate the variables which have been kept after the drop-off procedure

Fig. 8. Boosted regression trees for the accidental ignitions. The curve represents the mean value for 20 models. Values located above 0 are statistically significantly and positively associated with accidental ignitions, while values below 0 are statistically significantly and negatively associated with accidental ignitions. The stars indicate the variables which have been kept after the drop-off procedure

Fig. 9. Boosted regression trees for the ignitions due to negligence by professionals. The curve represents the mean value for 20 models. Values located above 0 are statistically significantly and positively associated with ignitions by negligence from professionals, while values below 0 are statistically significantly and negatively associated with ignitions by negligence from professionals. The stars indicate the variables which have been kept after the drop-off procedure

Fig. 10. Boosted regression trees for the ignitions due to negligence by private persons. The curve represents the mean value for 20 models. Values located above 0 are statistically significantly and positively associated with ignitions by negligence from private persons, while values below 0 are statistically significantly and negatively associated with ignitions by negligence from private persons. The stars indicate the variables which have been kept after the drop-off procedure 
Fig. 5

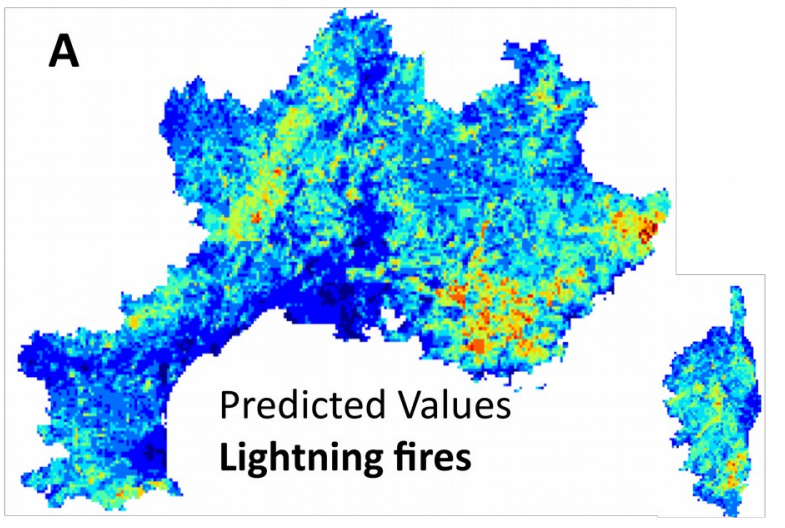

Fitted Values
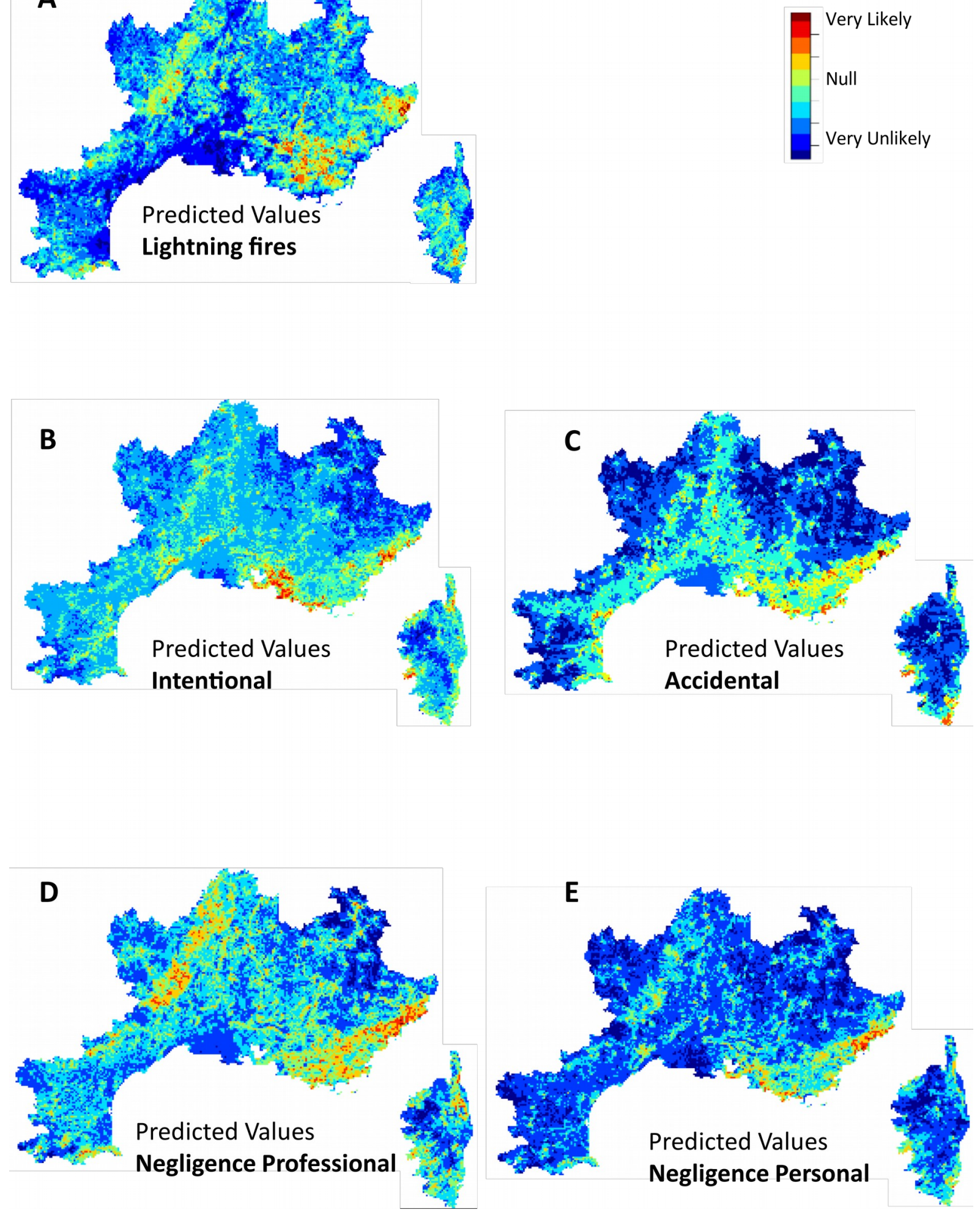
Fig. 6.
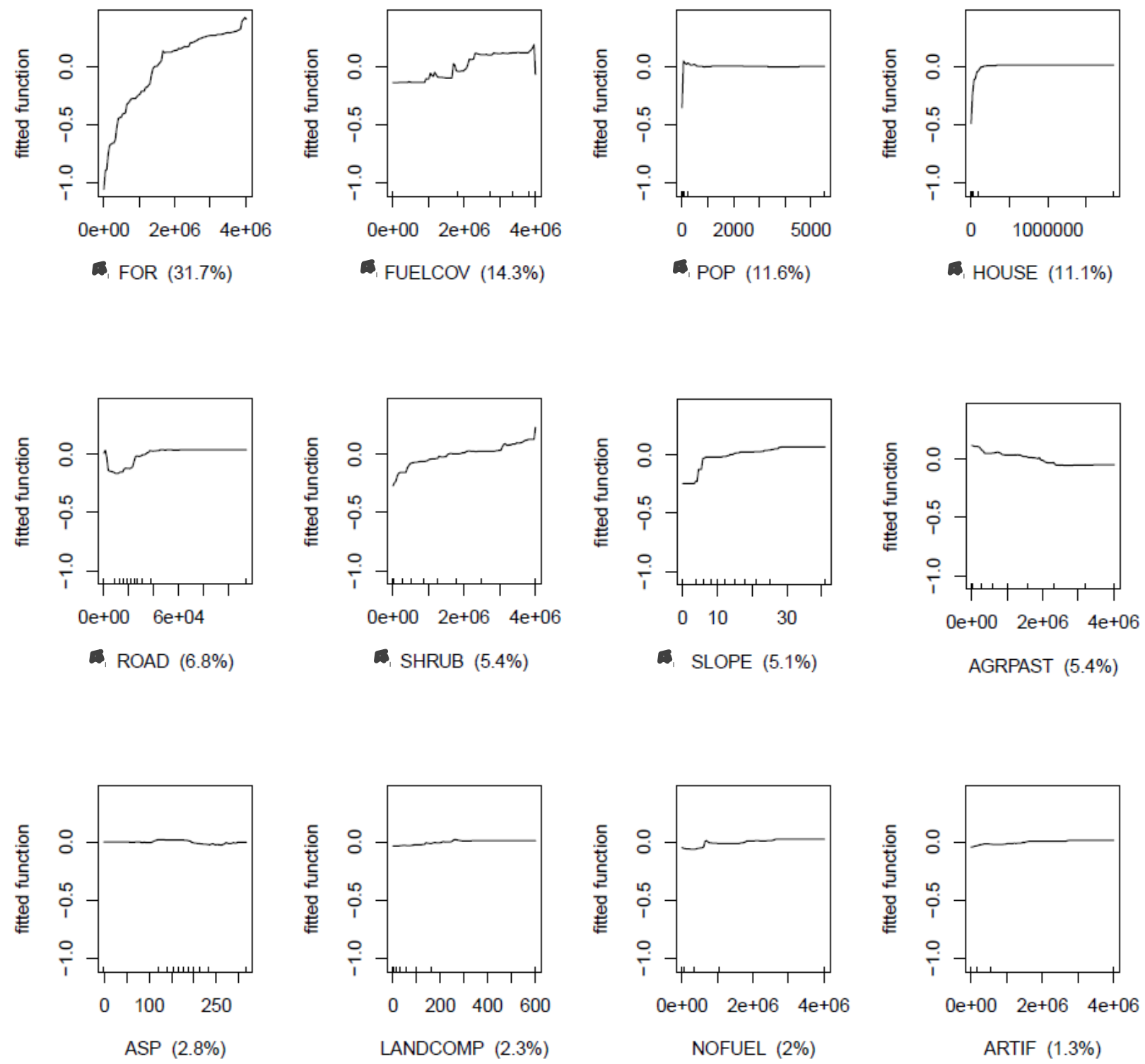
Fig. 7.
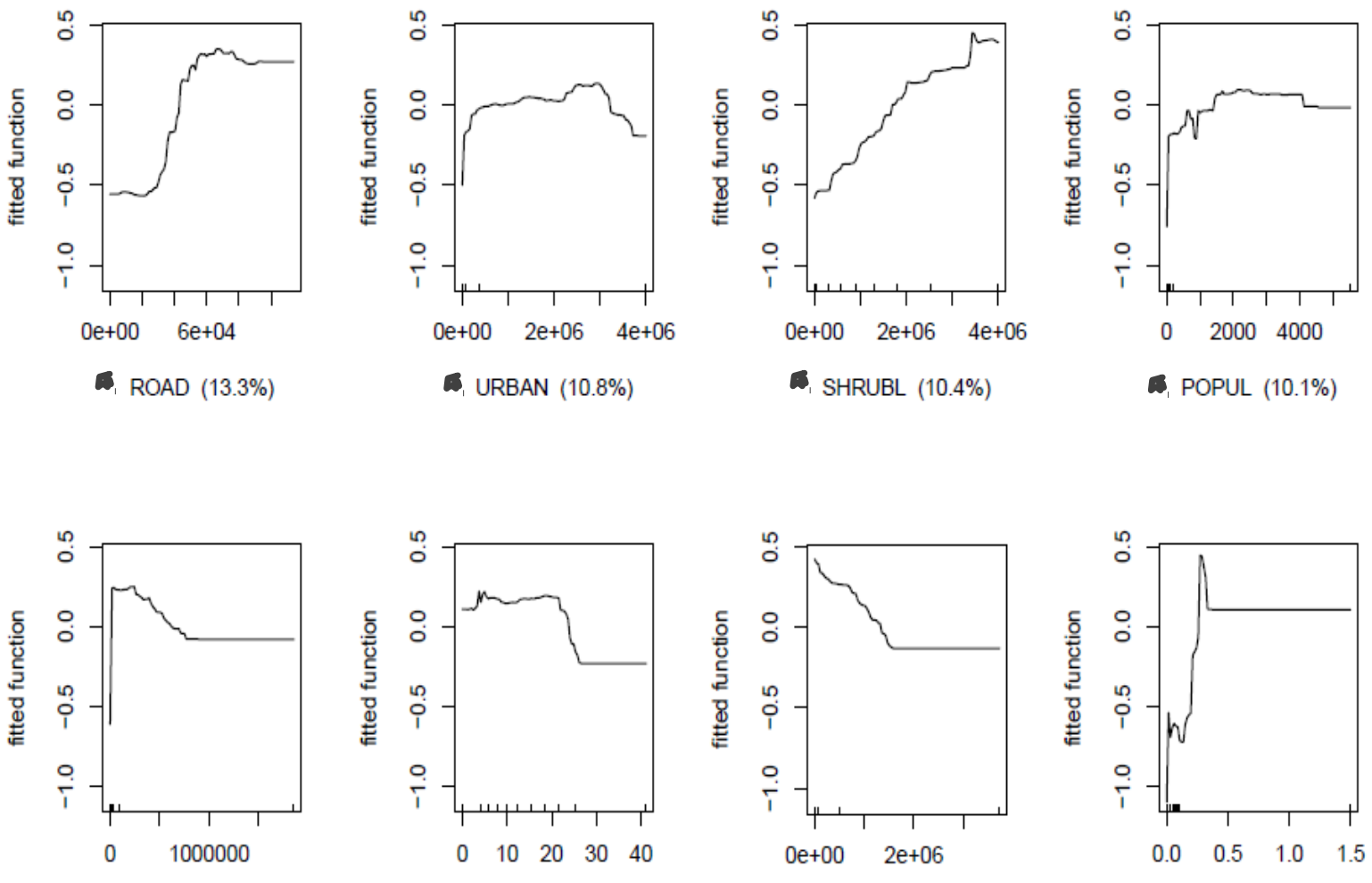

a HOUSES $(9.8 \%)$

- SLOPE $(8.9 \%)$

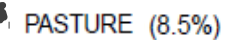

- UNEMPL $(7.8 \%)$
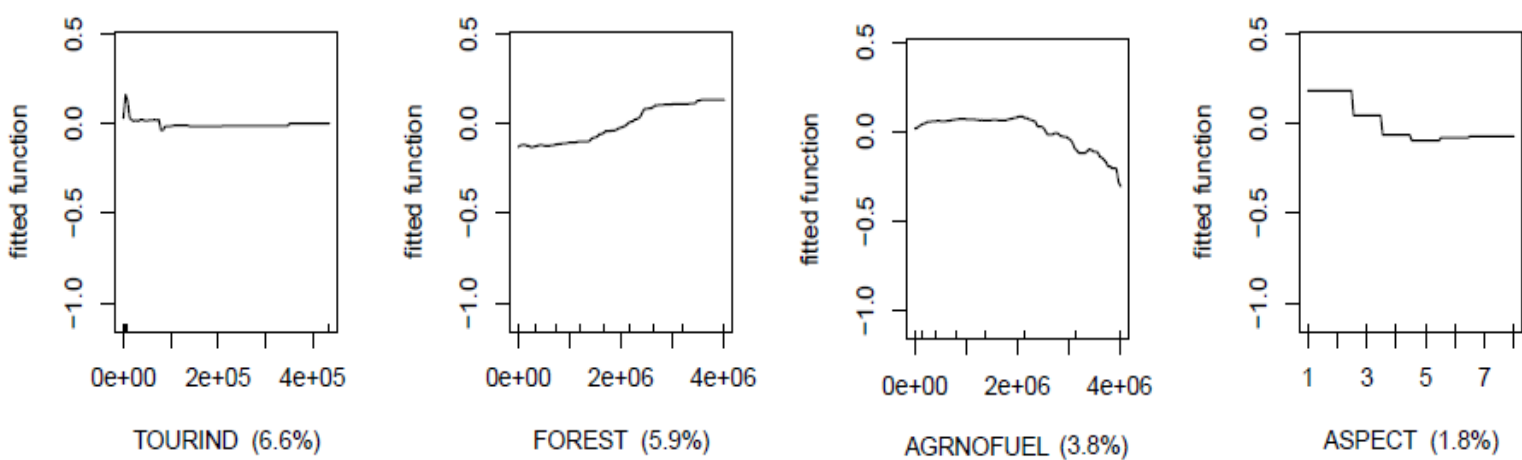

TOURIND (6.6\%) FOREST (5.9\%) 
Fig. 8.
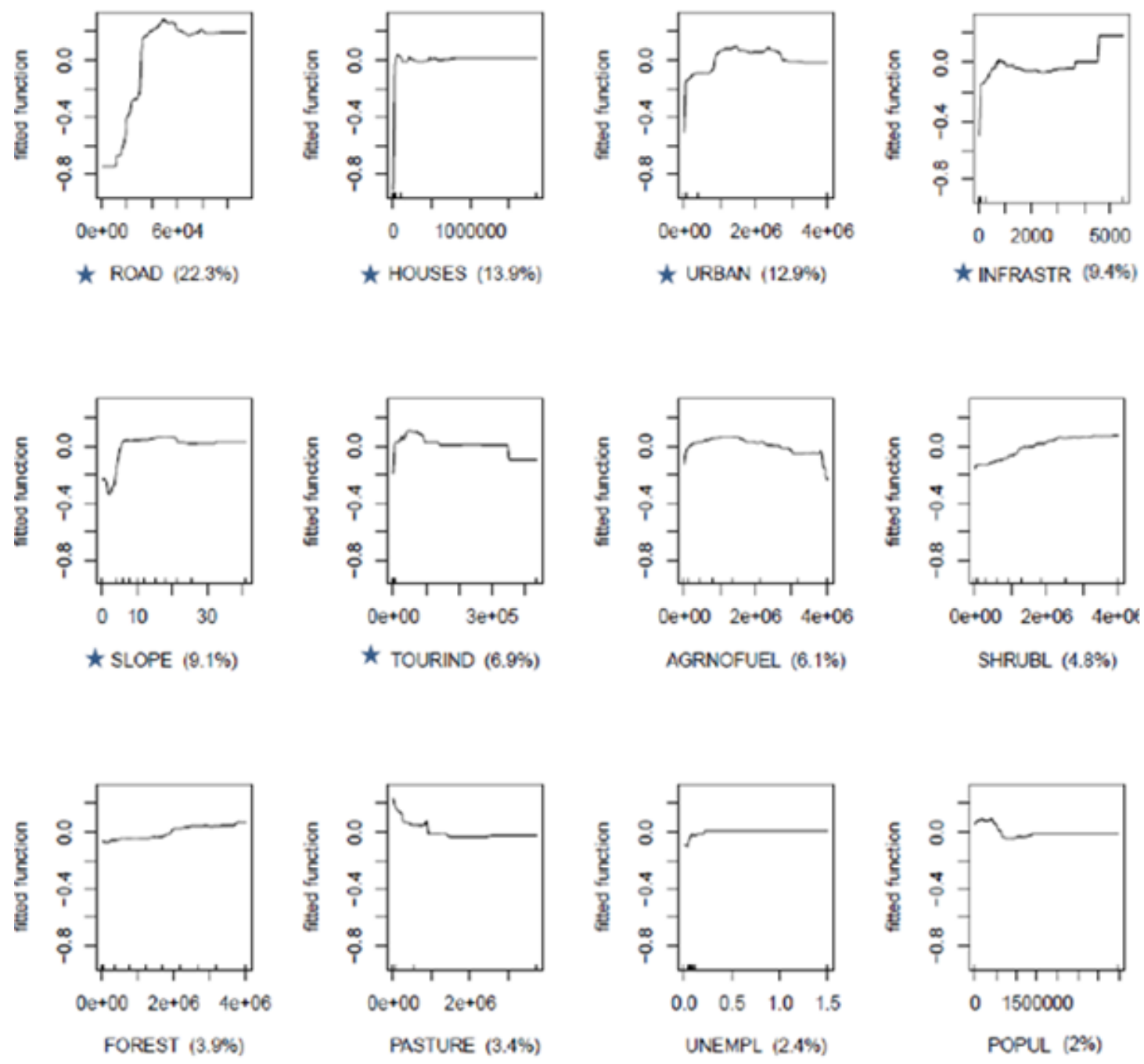
Fig. 9.

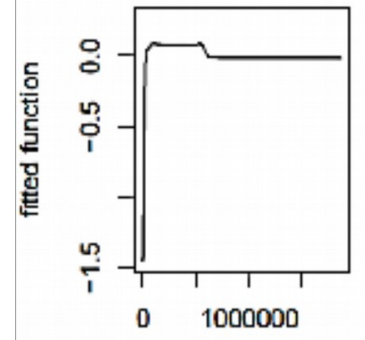

$\downarrow$ HOUSES (31.8\%)

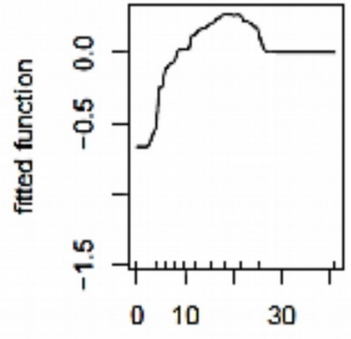

\ SLOPE (20.8\%)

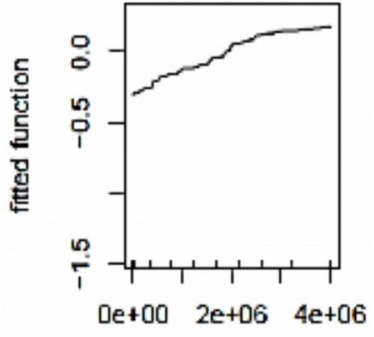

丸FOREST $(7.7 \%)$

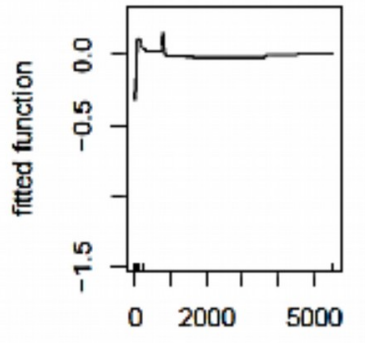

$\downarrow$ POPUL $(7.4 \%)$
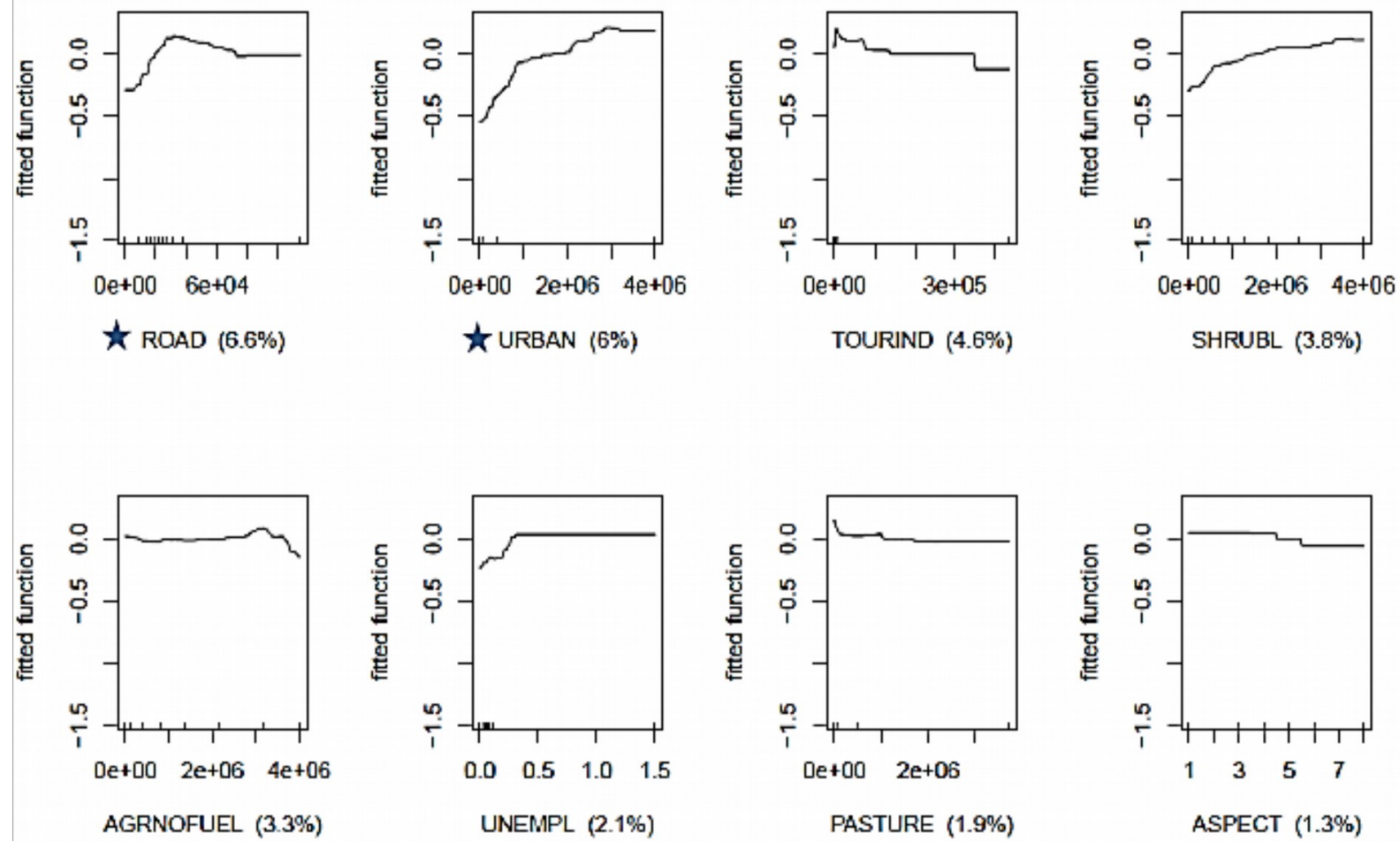
Fig. 10.

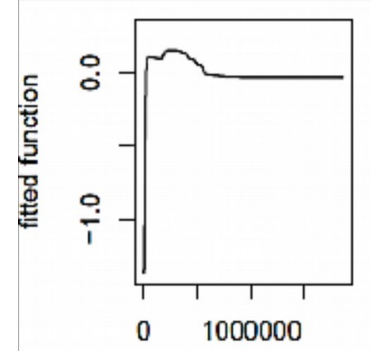

$\downarrow$ HOUSES (23.3\%)

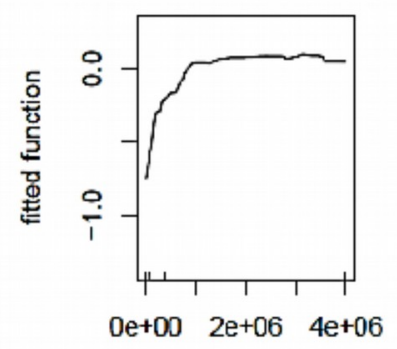

$\star$ \URBAN $(16.3 \%)$

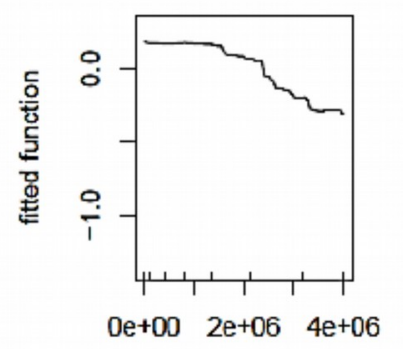

\AGRNOFUEL (12.5\%)

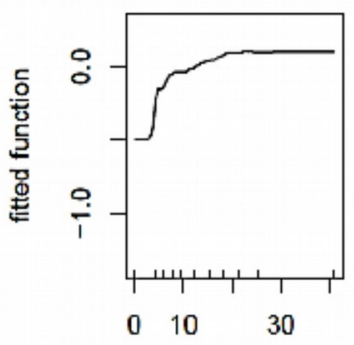

$\star$ SLOPE (11.4\%)

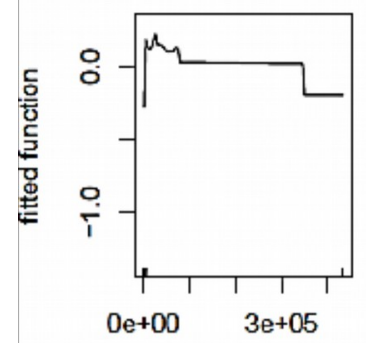

$\star$ TOURIND (7.9\%)

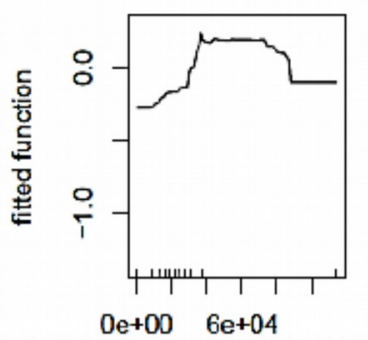

$\star$ ROAD $(6.5 \%)$

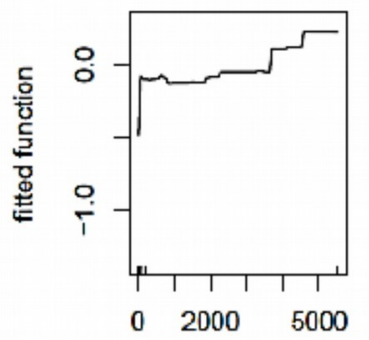

$\star$ POPUL (4.6\%)

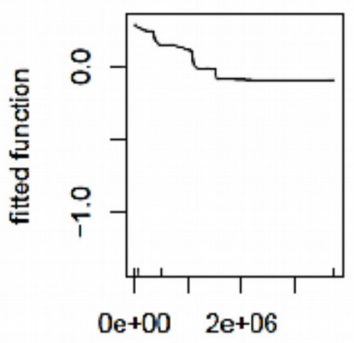

PASTURE (42\%)

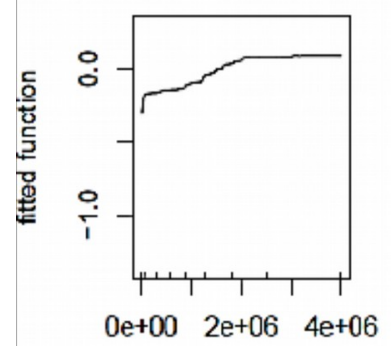

SHRUEL (4\%)

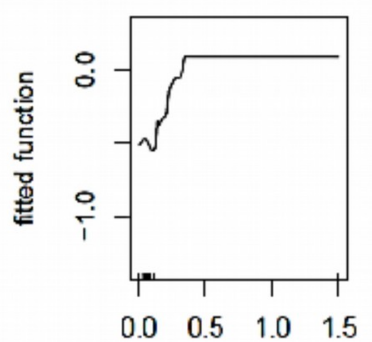

UNEMPL (3.6\%)

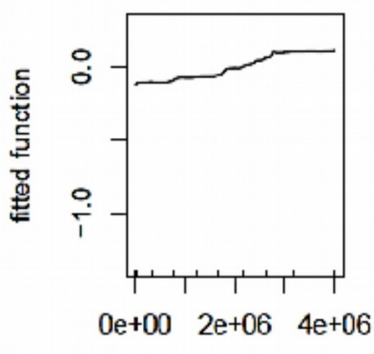

FOREST (3.1\%)

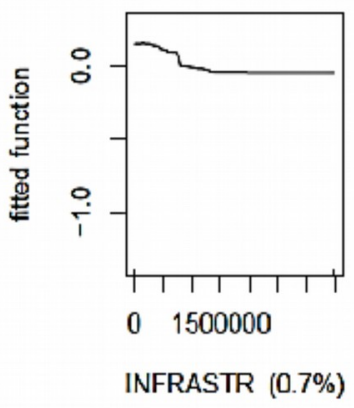

